\title{
High risk prescribing in primary care patients particularly vulnerable to adverse drug events: cross sectional population database analysis in Scottish general practice
}

\author{
Bruce Guthrie professor of primary care medicine ${ }^{1}$, Colin McCowan lecturer in health informatics ${ }^{1}$, \\ Peter Davey lead clinician for undergraduate clinical quality improvement ${ }^{1}$, Colin R Simpson senior \\ research fellow ${ }^{2}$, Tobias Dreischulte research pharmacist ${ }^{3}$, Karen Barnett research assistant ${ }^{1}$
}

${ }^{1}$ Quality, Safety and Informatics Research Group, Centre for Primary Care and Population Research, University of Dundee, Kirsty Semple Way, Dundee DD2 4BF, UK; ${ }^{2}$ Centre for Population Health Sciences, University of Edinburgh Medical School, Edinburgh, UK; ${ }^{3}$ Tayside Medicines Unit, NHS Tayside, Dundee, UK

\begin{abstract}
Objective To examine the prevalence and patterns of high risk prescribing, defined as potentially inappropriate prescribing of drugs to primary care patients particularly vulnerable to adverse drug events.

Design Cross sectional population database analysis.

Setting General practices in Scotland.

Participants 315 Scottish general practices with 1.76 million registered patients, 139404 (7.9\%) of whom were defined as particularly vulnerable to adverse drug events because of age, comorbidity, or co-prescription.

Main outcome measures How reliably each of 15 indicators-four each for non-steroidal anti-inflammatory drugs, co-prescription with warfarin, and prescribing in heart failure, two for dose instructions for methotrexate, and one for antipsychotic prescribing in dementia-and a composite of all 15 could distinguish practices in terms of their rates of high risk prescribing; and characteristics of patients and practices associated with high risk prescribing in a multilevel model.
\end{abstract}

Results 19308 of 139404 (13.9\%, 95\% confidence interval 13.7\% to $14.0 \%$ ) patients had received at least one high risk prescription in the past year. This composite indicator was a reasonably reliable measure of practice rates of high risk prescribing (reliability $>0.7$ for $95.6 \%$ of practices, $>0.8$ for $88.2 \%$ ). The patient characteristic most strongly associated with high risk prescribing was the number of drugs prescribed (>11 long term prescribed drugs $v 0$; odds ratio $7.90,95 \%$ confidence interval 7.19 to 8.68). After adjustment for patient characteristics, rates of high risk prescribing varied by fourfold between practices, which was not explained by structural characteristics of the practices.

Conclusions Almost $14 \%$ of patients defined as particularly vulnerable to adverse drug events were prescribed one or more high risk drugs. The composite indicator of high risk prescribing used could identify practices as having above average or below average high risk prescribing rates with reasonable confidence. After adjustment, only the number of drugs prescribed long term to patients was strongly associated with high risk prescribing, and considerable unexplained variation existed between practices. High risk prescribing will often be appropriate, but the large variation between practices suggests opportunities for improvement.

\section{Introduction}

Improving the safety of patients is an increasing priority for health policy and health services. Much work has focused on care in hospital, with less attention to major sources of harm in primary care, such as prescribing. Good evidence shows that prescribing in primary care causes considerable harm. Adverse drug events account for $6.5 \%$ of all hospital admissions, ${ }^{1}$ over half of which are judged to be preventable. ${ }^{2}$ The most commonly implicated drug classes are antiplatelet drugs, including aspirin, diuretics, non-steroidal anti-inflammatory drugs (NSAIDs), warfarin, opioids, $\beta$ blockers, and angiotensin converting enzyme inhibitors/angiotensin receptor blockers. ${ }^{2}$ Deaths from adverse drug events are most often associated with NSAIDs and prescribing of antiplatelets. ${ }^{1}$ Several national safety alerts have also been created for less commonly prescribed drugs implicated in preventable deaths. Examples include guidance on the prescribing and monitoring of methotrexate ${ }^{3}$ and antipsychotic use in older people with dementia. ${ }^{4}$

Although treatment in the United Kingdom may start in both primary and secondary care, general practitioners carry out almost all of the prescribing driving these admissions, as they prescribe virtually all drugs in the community and are responsible for drug reviews. However, few data exist on how common high risk prescribing is in primary care or how it varies between patients and between practices. For example, despite rapid changes in policy on antipsychotic use in older people with dementia, ${ }^{45}$ few population based studies have been carried 
out on rates of such prescribing ${ }^{6}$ and most have been small and usually based in nursing homes. ${ }^{5}$

Although there are several measures of potentially inappropriate prescribing, the Beers criteria are the ones most commonly used. These criteria consist of two drug lists: one of drugs that are potentially inappropriate in elderly people, such as long acting benzodiazepines, and another of drugs that may be inappropriate in elderly people with particular conditions, such as anticholinergics in chronic constipation. ${ }^{7}$ The Beers criteria can be assessed relatively easily in routine healthcare data and have been widely applied as a result, but most of the drugs listed are rarely used and the list does not include many of the drugs most associated with serious harm or with emergency hospital admission. More recently developed tools include drug items in the Assessing Care of Vulnerable Elders project ${ }^{8}$ and the screening tool of older persons potentially inappropriate prescriptions (STOPP). The screening tool is better associated with harm in older people admitted to hospital than are the Beers criteria, but both tools require record review to implement, precluding large scale or routine use. ${ }^{9} 10$

We examined the frequency of high risk prescribing in patients particularly vulnerable to adverse drug events, how reliably the indicators could distinguish between practices (which is critical if indicators are to be used to measure practices for high stakes evaluation, including performance management and clinical governance), and patient and practice characteristics associated with high risk prescribing.

\section{Methods}

Using the dataset held by the Primary Care Clinical Information Unit at the University of Aberdeen, we extracted data from 315 general practices in Scotland contributing to the Scottish programme for improving clinical effectiveness in primary care (SPICE-PC), with analysis based on complete data as at 31 March 2007. Thirty one per cent of Scottish practices contributed data, covering a population representative of Scotland for age, sex, and deprivation, and including patients living in their own homes or in nursing homes. ${ }^{11}$

\section{Population}

We extracted data for all patients permanently registered on 31 March 2007 who were defined as being particularly vulnerable to one of the specified prescriptions because of age, pre-existing disease (heart failure, dementia, chronic kidney disease, peptic ulcer), or pre-existing co-prescription (warfarin, angiotensin converting enzyme inhibitor, angiotensin receptor blocker, diuretic). We used the disease register business rules of the UK Quality and Outcomes Framework to define heart failure, chronic kidney disease, dementia, and psychosis, with a bespoke Read code set used to define peptic ulcer disease. ${ }^{12}$

For each patient we also extracted data on age; sex; postcode assigned deprivation, using the Carstairs score (grouped into fifths $)^{13}$; and number of oral drugs on active repeat prescription, with at least one prescription issued in the past 84 days. Variables defined at practice level were rurality or remoteness based on the Scottish Executive urban-rural classification, list size (grouped into fourths), whether the practice held a new General Medical Services or section $17 \mathrm{c}$ or $2 \mathrm{c}$ contract (the Scottish equivalent of a Personal Medical Services contract where there is local variation from the national new General Medical Services template), postgraduate training status, dispensing status, whether the practice was single handed, and whether the practice achieved maximum points for three relevant drug measures in the Quality and Outcomes Framework: medicines 10 , where practices are paid for meeting prescribing advisers and agreeing three improvement projects for the subsequent year, with evidence of delivery of the previous year's agreed projects, and medicines 11 and 12 where practices are paid for carrying out drug reviews on more than $80 \%$ of patients taking repeat drugs, with extra payment for achieving this for patients taking four or more repeat drugs. ${ }^{12}$

\section{Outcome definition}

Given the limitations of existing indicator sets described above, we defined a new set of indicators of hazardous prescribing for drugs prescribed in situations identified as clearly high risk in national safety alerts ${ }^{3-14}$ and commonly implicated in serious harm, as measured by emergency hospital admission due to an adverse drug event. ${ }^{12}$ Indicators were required to be ones where the prescribing being measured was clearly stated to be contraindicated or to be avoided in routine practice, either in the British National Formulary, ${ }^{15}$ national clinical guidelines, ${ }^{16}$ prescribing advice, ${ }^{14-19}$ or safety alerts. ${ }^{3}$ It is important to recognise that most patients receiving such prescriptions will not be harmed and few of these prescriptions are absolutely contraindicated. However, for every indicator examined there was explicit guidance at the time of prescription that it carried significant risk of harm and should be routinely avoided, usually on the basis of clear evidence that such prescribing carried a significantly increased risk to patients. Candidate indicators were rated in a modified RAND process ${ }^{20}$ involving a panel of four general practitioners (two with roles in improving prescribing at primary care organisation level) and six pharmacists (two with an academic interest in safe prescribing, the remainder with pharmacy roles in both primary care organisation and hands-on practice). Included indicators were all rated as "necessary to avoid" (median score $>7$ on a 9 point scale, with no disagreement within the pane ${ }^{20}$ ). Indicators were additionally required to be measureable using routine electronic clinical data in primary care, which precluded those based on laboratory monitoring that is inconsistently recorded in general practice records. Notably, we excluded indicators related to warfarin and hypoglycaemic drug monitoring.

The outcomes measured were receipt of a drug defined as high risk prescribing for a patient because of their age, a pre-existing condition, or they were already prescribed drugs that could potentially interact with the ones being prescribed. The period over which receipt of a drug was measured varied from the past 12 weeks for co-prescription and dose instructions for methotrexate to one year for prescription to people defined as vulnerable to adverse drug events because of age or comorbidity. We defined 15 individual indicators (table 1). For each indicator we extracted details of relevant drug prescribing recorded in the electronic record in the year from 1 April 2006 to 31 March 2007. Drug definitions used codes from the British National Formulary supplemented with free text name searches where necessary. For example, for the measure

"Risperidone/olanzapine prescribed in over-65s with dementia but not psychosis," we included patients if their electronic record had a relevant Read code for the presence of dementia (excluding those with a Read code for the presence of psychosis or serious mental illness, as defined by the Quality and Outcomes Framework, where a prescription for antipsychotics is more clearly indicated). We then measured the proportion of such patients with an electronic record of prescription for risperidone or olanzapine in the 12 weeks before 31 March 2007. In addition, an overall composite indicator was also defined as whether or not the patient had received any high risk prescription. 


\section{Statistical analysis}

For each indicator we calculated the proportion of patients receiving a high risk prescription, with $95 \%$ confidence intervals. We also determined the reliability of indicators in distinguishing between practices. Reliability in this context refers to how accurately an indicator measures an individual practice's performance based on a mean score of a patient level outcome. It is therefore a measure of how confident we can be that observed differences between practices result from true differences in prescribing safety. ${ }^{29}$ Reliability increases as variation between practices increases (measured by the intracluster correlation coefficient, which is estimated using all the data and is the same for all practices) and as the number of patients being measured in the practice increases. An indicator may therefore be reliable for a large practice but not for a small one. For an indicator to be used routinely to compare practices for performance management or governance purposes, it requires adequate reliability for as many of the practices being measured as possible. Reliability varies between 0 (completely unreliable) and 1 (completely reliable). Values greater than 0.7 are generally considered to indicate acceptable reliability in the sense that observed differences between practices can be reasonably confidently attributed to true differences in quality or safety. For high stakes evaluation, reliabilities of 0.8-0.9 are preferable. ${ }^{29-31}$

We estimated the intracluster correlation coefficient for each indicator in an empty multilevel logistic regression model, and the reliability of each indicator and the composite calculated using the Spearman-Brown prophecy formula for a notional practice, with the median number of patients being measured by the indicator. Based on the actual number of patients being measured in each practice, for each indicator we additionally calculated the proportion of practices with reliability of greater than 0.7 and greater than $0.8 .^{30} 31$

We used multilevel logistic regression to examine how the composite indicator of receipt of at least one high risk prescription varied between practices and by patient and practice characteristics. For patient and practice variables we calculated multilevel univariate odds ratios. Two multivariate (adjusted) models were estimated, with patient level variables fitted first and variables retained based on statistical significance using a Wald test. For both models we estimated the explained variance $\left(\mathrm{R}^{2}\right) .{ }^{32}$ We examined variation between practices after controlling for differences in case mix by plotting on a cross sectional control chart the observed versus expected numbers of patients with a high risk prescription. ${ }^{33} \mathrm{~A}$ sensitivity analysis was carried out to examine whether dropping the least reliable individual indicators improved the composite reliability or changed the overall conclusions from multilevel regression. All models were fitted with second order penalised quasi-likelihood estimation, and assumptions of normality of level 2 residuals and other model diagnostics checked graphically. Initial analysis was carried out in SPSS v17.0, and multilevel logistic regression in MIWin 2.0 (Centre for Multilevel Modelling, University of Bristol, UK).

\section{Results}

Overall, 139404 of 1760223 (7.92\%, 95\% confidence interval $7.88 \%$ to $8.00 \%$ ) patients were defined as being particularly vulnerable to adverse drug events because of their age, pre-existing disease, or co-prescription. Table 2 shows the rate of high risk prescribing for each of the indicators, which varied from $0.5 \%$ to $50.5 \%$. In total, $19.7 \%$ (95\% confidence interval $19.1 \%$ to $20.3 \%$ ) of patients prescribed warfarin had received a high risk prescription in the past year (most commonly for antiplatelets or high risk antibiotics), and $18.2 \%$ (17.6\% to $18.7 \%$ ) of patients with heart failure had been prescribed a drug that was contraindicated or recommended to be avoided (most commonly NSAIDs or tricyclics). Other high risk prescribing of NSAIDs was also relatively common, with rates ranging from $4.1 \%$ of older people with renal impairment to $50.5 \%$ of over $75 \mathrm{~s}$ prescribed an NSAID without gastroprotection. Most patients prescribed an NSAID had received multiple prescriptions for these drugs in the previous year. In total, 19 308 of the 139404 patients particularly vulnerable to adverse drug events $(13.9 \%$, 95\% confidence interval $13.7 \%$ to $14.0 \%)$ had received at least one high risk prescription in the past year. Overall, 16423 (84.1\% of those receiving any high risk drug) patients received only one type of high risk prescription, 2530 $(13.1 \%)$ two, and $546(2.8 \%)$ three or more.

\section{Reliability of indicators in distinguishing between practices}

Variation between practices in the overall rate of high risk prescribing measured by the composite was considerable, ranging from $3.6 \%$ of patients receiving at least one high risk prescription to $31.3 \%$ (median $12.5 \%$, interquartile range 10.1-15.3\%). Twelve of the 15 indicators (excluding the warfarin and heart failure composites) had adequate reliability ( $>0.7)$ for a median sized practice, but significant numbers of practices had too few patients to be reliably measured. Depending on the indicator, between $31.7 \%$ and $91.7 \%$ of practices had reliability greater than 0.7 , and between $7.6 \%$ and $80.3 \%$ had reliability greater than 0.8 . The reliability of the composite for a median sized practice was 0.92 , with reliability greater than 0.7 in $95.6 \%$ of practices and greater than 0.8 in $88.2 \%$.

\section{Patient and practice characteristics associated with high risk prescribing}

Table 3 shows the percentage of patients receiving at least one high risk prescription by a range of patient and practice characteristics, and univariate odds ratios estimated in a multilevel model. High risk prescribing increased noticeably with the number of drugs recently issued on a repeat prescription, with $4.3 \%$ of patients with no long term prescribed drugs receiving a high risk prescription compared with $26.6 \%$ of those prescribed 11 or more drugs long term (difference in proportions $22.2 \%, 95 \%$ confidence interval $21.1 \%$ to $23.3 \%$ ). High risk prescribing also increased with age, rising progressively from $6.7 \%$ in the under 40 s to $15.9 \%$ in $70-79$ year olds, but decreasing to $13.2 \%$ in those aged 80 and over (difference for age $<40 v 70-799.2 \%, 95 \%$ confidence interval $8.3 \%$ to $10.1 \%$ ). Other patient level variables had smaller associations, although still statistically significant. Women were more likely to receive a high risk prescription (14.6\% v $13.1 \%$ in men, difference $1.5 \%, 1.1 \%$ to $1.8 \%$ ) as were patients living in more socioeconomically deprived areas $(15.3 \% v 12.8 \%$ for those living in the most affluent areas, difference $2.5 \%, 1.9 \%$ to $3.1 \%$ ). High risk prescribing varied less by practice level variables, with higher rates in smaller practices compared with large practices, in non-training practices, and in practices with a section $2 \mathrm{c}$ or $17 \mathrm{c}$ (Personal Medical Services) contract.

In the multivariate model including only patient level variables (table 4, model 1), the association of high risk prescribing with the number of active repeat drugs was largely unchanged. Associations with age and sex were weaker in the adjusted model and, although statistically significant, were small in absolute terms. Associations with deprivation were found to be no longer significant. The patient level variables in model 1 
explained $8.1 \%$ of the variance in receipt of a high risk prescription. Three practice variables were significantly associated with high risk prescribing in the adjusted model (table 4 , model 2). Compared with smaller practices (list size <4675), patients in the largest practices (list size $>9876$ ) were less likely to receive a high risk prescription. Patients in non-training practices were more likely to receive a high risk prescription as were patients in urban and accessible areas compared with primary cities. However, the absolute differences and the adjusted odds ratios were all small, and adding practice variables only explained an additional $0.5 \%$ of the variance in receipt of a high risk prescription $\left(\mathrm{R}^{2}=8.6 \%\right.$ for model $2 v 8.1 \%$ for model 1).

Variation between practices was considerable even after adjusting for case mix in terms of the patient level variables in model 1 . The figure shows how the observed numbers of patients with a high risk prescription differed from expected in each practice after adjustment for patient case mix. Practices lying outside the 3 standard deviation control limit were statistically significantly different from the average, and varied from having half the expected rates of high risk prescribing to having a $50-125 \%$ excess. The median odds ratio for two patients randomly selected from different practices was $1.42(95 \%$ confidence interval 1.37 to 1.47$).{ }^{34}$

In the sensitivity analysis, reanalysing the data after dropping the three least reliable indicators (prescribing NSAIDs to older patients without gastroprotection, prescribing mixed strengths of methotrexate, and prescribing high risk antibiotics to patients taking warfarin) did not substantively alter the findings or their interpretation. The reliability of the 12 indicator composite was 0.92 for the median sized practice, and reliability was greater than 0.7 for $94.9 \%$ of practices and greater than 0.8 for $87.6 \%$ (sensitivity analysis multilevel modelling data not shown).

\section{Discussion}

As measured by the 15 indicators examined, high risk prescribing is relatively common, with $13.9 \%$ of patients particularly vulnerable to adverse drug events receiving one or more high risk prescriptions in the past year. Although individual indicators did not reliably distinguish practices, the composite indicator of whether or not patients had received one or more high risk prescriptions in the past year was reasonably reliable, with $95.6 \%$ of practices having greater than 0.7 reliability and $88.2 \%$ greater than 0.8 . The implication is that we can be reasonably confident that the composite indicator correctly defines practices as having above average or below average rates of high risk prescribing (whereas we cannot be confident that the individual indicators do so).

In multilevel logistic regression analysis, only the number of drugs the patient was being prescribed long term was strongly associated with high risk prescribing, but considerable unexplained variation existed between practices. Although several other patient level and practice level variables were statistically significantly associated with receipt of a high risk prescription, the odds ratios for these were close to one in the adjusted model, and the clinical significance of these associations is marginal. Notably, after adjustment for patient level variables, patients in the lowest prevalence practices had about half the expected rate of high risk prescribing, whereas the highest prevalence practices had 50-125\% more patients with high risk prescribing than expected (figure). This variation at practice level was not explained by the structural characteristics of the practices included in the model, and in particular was not associated with performance measured by the three Quality and Outcomes Framework management indicators for medicines that we examined. ${ }^{12}$

\section{Strengths and weaknesses of the study}

To our knowledge, this is the first large scale study of prescribing safety in primary medical care that uses multiple indicators based on explicit national prescribing safety advice, and examines how high-risk prescribing varies between both patients and practices in a highly representative population. The study has several important limitations. Firstly, although the prescribing being measured is defined as high risk in national guidance, it is not always inappropriate. This is because real life prescribing often involves balancing risk and benefit in conditions of uncertainty, and a drug may be high risk but still a rational and reasonable one to prescribe. Unlike situations such as the surgical excision of a healthy right sided kidney instead of a diseased left sided one, few of these indicators are therefore measuring "never events" where the care given is unequivocally wrong. ${ }^{35}$ However, given that all the prescribing examined is stated in national guidance to be contraindicated or to be avoided in routine practice, the high rates and large variation between practices is consistent with a significantly appropriate proportion of prescribing examined.

Secondly, because of constraints on feasibility, the indicators used represent only a selection of possible important measures. For example, although both warfarin and hypoglycaemic drugs contribute significantly to emergency hospital admission with adverse drug events, ${ }^{12}$ variable recording of laboratory data meant that we could not include indicators relating to warfarin monitoring in this analysis, and indicators for safe use of hypoglycaemic drugs in diabetes were not feasible. The indicator set is therefore not comprehensive, reflecting the difficulty in capturing the full complexity of prescribing electronically. Additionally, over the counter purchase of ibuprofen from pharmacies is not recorded electronically in general practice clinical systems. This study is therefore likely to significantly under-estimate the true rate of high risk prescribing by general practitioners and wider use of high risk medicines.

Thirdly, variation between practices may be due to unmeasured heterogeneity in case mix, such as varying comorbidity (although this is likely to be significantly accounted for by the variable relating to the number of drugs prescribed long term). Finally, although the study identified significant variation in high risk prescribing between practices, it did not examine variation between individual doctors within the practices. The study therefore could not distinguish between practices with generalised high risk prescribing and practices with individual prescribers who are higher than average risk. Both are likely to be important. If high risk prescribing was largely driven by individuals, however, it seems likely that practice list size would be a stronger predictor, since individual effects should be progressively diluted in larger practices.

\section{Unanswered questions and future research}

Several areas of uncertainty would benefit from further research. The first relates to validity, or the degree to which an indicator measures what it claims to, in this case high risk prescribing. The indicators examined have strong face validity because they are all subject to explicit national guidance, and most are underpinned by a strong evidence base that quantifies the risk involved. For example, the current evidence from randomised controlled trials is that treating 100 people with dementia with an antipsychotic for 6-12 weeks is associated with one additional death. It is estimated that prescribing of antipsychotics in people 
with dementia is associated with 1620 additional strokes (half severe) and 1800 additional deaths per year in the United Kingdom. This might be acceptable if antipsychotics had large benefits in this population, but they do not. ${ }^{5}{ }^{14}$ However, the evidence base underlying some other indicators is weaker, which makes explicit consideration of risks and benefits of a particular drug to an individual difficult. For example, the significant risk of co-prescribing antiplatelet drugs and NSAIDs to people taking warfarin is well quantified. ${ }^{21-23}$ Yet despite the toxicity of warfarin and the frequency with which it is prescribed, there are few precise estimates of the risk of other co-prescribed drugs, including antibiotics. ${ }^{21}$ The growth of large, linkable electronic databases should allow more systematic study of the risks of prescribing in primary care in the future. Further evidence of validity would come from intervention studies showing that rates of high risk prescribing can be reduced, and ideally that patient harm is reduced as a result.

Secondly, although this study identified that high risk prescribing varied considerably between practices, none of the practice level variables examined accounted for this variation. Potentially useful areas to explore are whether practice rates of high risk prescribing are driven more by a small number of individual prescribers or are more strongly related to wider practice organisation and culture of prescribing safety. ${ }^{36}$ Both are likely to contribute, but practice culture and organisation are likely to be important because clinical care and responsibility for generating, checking, and signing repeat prescriptions is almost always shared. Further work is therefore required to understand better the sources of variation between practices, and an additional priority is to rigorously develop and test interventions targeting individuals or practices. ${ }^{37}$

Thirdly, research is needed to understand better and improve existing mechanisms for making prescribing safer. From this perspective, the most effective way to implement drug alerts in general practice clinical IT systems is uncertain. The data examined here came from a system in which drug interaction alerts were routine, were tiered (using a traffic light system to flag more serious interactions), and were non-interruptive (alerts are advisory and do not require the prescriber to explicitly over-ride them). Other IT systems also include drug-disease warnings ${ }^{38}$ and vary in tiering and whether prescribers have to over-ride alerts. A need exists for comparison of high risk prescribing rates in practices using different prescribing decision support systems. However, such alerts only trigger when a drug is newly prescribed, which means that patients receiving high risk drugs authorised for repeat prescribing are not explicitly flagged during subsequent drug review. The Quality and Outcomes Framework includes incentives for carrying out drug reviews for such patients, but there is little guidance as to the content of such reviews, ${ }^{12}$ and in this study it is notable that there was no relation between high risk prescribing and achieving maximum Quality and Outcomes Framework points for the three drug review and medicines improvement activity measures examined. Research that examines how to make drug review more effective is needed.

\section{Conclusions and implications for policy and practice}

From a clinical and health services perspective, this study shows that opportunities to improve primary care prescribing safety are considerable. The composite indicator used in this study has strong face validity because the indicators underlying it are all based on national guidance, and there is strong epidemiological evidence of harm for most indicators included. It is also a reliable enough measure to be used to distinguish practices with high and low rates of high risk prescribing. In principle, this kind of composite could therefore be used for the purposes of clinical governance and performance management-for example, by identifying practices with particularly high rates of high risk prescribing for further investigation. ${ }^{30} 39$

In practice major reductions in high risk prescribing are likely to require improvement across the whole distribution of practices to shift the average rather than solely focusing on outliers. It is also important to recognise that not all high risk prescribing is inappropriate, so the "correct" rate for indicators like these is unlikely to be zero. Routine electronic data can measure rates of high risk prescribing, but record or patient review will usually be needed to properly judge appropriateness. From a quality improvement perspective, the best use of these indicators is therefore likely to be to target drug review for patients receiving high risk prescriptions, prompting the explicit application of clinical judgment to questions of appropriateness. The findings suggest that existing activity to improve prescribing is insufficiently focused on safety, despite the considerable harm caused by prescribing. This possibly reflects both the historical background of improving prescribing by focusing on costs and the lack of routinely available indicators of prescribing safety. The current ubiquity of electronic data in UK primary care makes routine measurement of the kind carried out in this study feasible, and it is time to make prescribing safety a priority in primary care.

We thank the practices who contributed data to the Scottish programme for improving clinical effectiveness in primary care and allowed the anonymised data to be used for research; staff at the Primary Care Clinical Information Unit at University of Aberdeen who carried out the initial data extraction and management, particularly Katie Wilde and Fiona Chaloner; and project advisory group members Lorna Scahill and Mairi Scott.

Contributors: BG conceived the study and planned it with $\mathrm{CMCC}, \mathrm{PD}$, and CRS, with TD leading the literature review. KB and BG carried out the analysis. All authors contributed to the writing of the paper. BG is the guarantor.

Funding: This work was supported by NHS Quality Improvement Scotland (Better Measures project grant supporting KB) and the Scottish Government Chief Scientist Office (applied research programme grant 07/02 supporting TD, and Health Services and Health of the Public postdoctoral fellowship PDF/08/02 supporting CRS), but study design, data analysis, interpretation and publication were the responsibility of the research team, who had sole access to the data.

Competing interests: All authors have completed the ICMJE uniform disclosure form at www.icmje.org/coi_disclosure.pdf (available on request from the corresponding author) and declare: that KB was supported by a project grant (Better Measures) from NHS Quality Improvement Scotland, TD was supported by an applied research programme grant (07/02) from the Scottish Government Chief Scientist Office, and CRS was supported by a health services and health of the public postdoctoral fellowship (PDF/08/02); no financial relationships with any organisations that might have an interest in the submitted work in the previous three years; no other relationships or activities that could appear to have influenced the submitted work.

Ethical approval: Not required; all data were fully anonymised and data use was compliant with the Primary Care Clinical Informatics Unit research governance process.

Data sharing: No additional data available.

Pirmohamed M, James S, Meakin S, Green C, Scott AK, Walley TJ, et al. Adverse drug reactions as cause of admission to hospital: prospective analysis of 18820 patients. BMJ 2004;329:15-9. 


\section{What is already known on this topic}

Preventable adverse drug events related to prescribing in primary care are a common cause of hospital admission and death

Potentially inappropriate prescribing has been shown to be relatively common using various indicator sets

Existing indicator sets do not always measure prescribing of drugs most commonly associated with harm or cannot be applied in routine clinical data

\section{What this study adds}

$14 \%$ of patients defined as particularly vulnerable to adverse drug events because of age, pre-existing disease, or co-prescription had received a high risk prescription in the past year

High risk prescribing was much more common in patients prescribed long term drugs

Significant variation between practices was not explained by patient case mix or by a range of practice structural factors

2 Howard R, Avery A, Slavenburg S, Royal S, Pipe G, Lucassen P, et al. Which drugs cause preventable admissions to hospital? A systematic review. Br J Clin Pharmacol 2007;63:136-47.

3 National Patient Safety Agency. Improving compliance with oral methotrexate guidelines. NPSA, 2006.

4 Medicines and Healthcare Products Regulatory Agency, Commission on Human Medicines. Antipsychotics: use in elderly people with dementia. Drug Saf Update 2009;2:8.

5 Banerjee $\mathrm{S}$. The use of antipsychotic medication for people with dementia: time for action. Department of Health, 2009.

6 Guthrie B, Clark SA, McCowan C. The burden of psychotropic drug prescribing in people with dementia: a population database study. Age Ageing 2010;39:637-42.

7 Fick DM, Cooper JW, Wade WE, Waller JL, Maclean JR, Beers MH. Updating the Beers criteria for potentially inappropriate medication use in older adults. Arch Intern Med 2003;163:2716-24.

8 Higashi T, Shekelle P, Solomon DH, Knight E, Roth CP, Chang J, et al. The quality of pharmacological care for vulnerable older patients. Arch Intern Med 2004;140:714-20.

9 Gallagher P, O'Mahony D. STOPP (Screening Tool of Older Persons' potentially inappropriate Prescriptions): application to acutely ill elderly patients and comparison with Beers' criteria. Age Ageing 2008;37:673-9.

10 Gallagher P, Ryan C, Byrne S, Kennedy J, O'Mahony D. STOPP (Screening Tool of Older Person's potentially inappropriate Prescriptions) and START (Screening Tool to Alert doctors to Right Treatment). Consensus validation. Int J Clin Pharmacol Ther 2008;46:72-83.

11 Elder R, Kirkpatrick M, Ramsay W, MacLeod M, Guthrie B, Sutton M, et al. Measuring quality in primary medical services using data from SPICE. NHS National Services Scotland, 2007

12 NHS England. Primary care commissioning. QOF implementation: business rules. NHS England, 2009.

13 Carstairs V, Morris R. Deprivation and health in Scotland. Aberdeen University Press, 1991.

14 Committee on Safety of Medicines. Summary of clinical trial data on cerebrovascular adverse events (CVAEs) in randomized clinical trials of risperidone conducted in patients with dementia. Committee on Safety of Medicines, 2004.

15 British Medical Association, Royal Pharmaceutical Society of Great Britain. British national formulary. BMA, RPS, 2007 (No 54).

16 Scottish Intercollegiate Guidelines Network. SIGN 95: management of chronic heart failure. SIGN, 2007

17 Medicines and Healthcare Products Regulatory Agency, Commission on Human Medicines. Rosiglitazone and pioglitazone: cardiovascular safety. Drug Saf Update 2007;1:5.

18 Medicines and Healthcare Products Regulatory Agency, Commission on Human Medicines. Non-steroidal anti-inflammatory drugs: cardiovascular risk. Drug Saf Update 2009;2:7.

19 NHS National Prescribing Centre. Cardiovascular and gastrointestinal safety of NSAIDs NHS National Prescribing Centre, 2007.

20 Fitch K, Bernstein S, Aguilar M, Burnand B, LaCalle J, Lazaro P, et al. The RAND/UCLA appropriateness method user's manual. RAND Corporation, 2003.

21 Holbrook AM, Pereira JA, Labiris R, McDonald H, Douketis JD, Crowther M, et al. Systematic overview of warfarin and its drug and food interactions. Arch Intern Med 2005;165:1095-106.
22 NHS National Prescribing Centre. Combination antithrombotics: are the benefits worth the bleeding risk? NHS National Prescribing Centre, 2006.

23 Delaney JAM, Opatrny LMDM, Brophy JMMDP, Suissa SP. Drug drug interactions between antithrombotic medications and the risk of gastrointestinal bleeding. Can Med Assoc J 2007;177:347-51

24 Loboz K, Shenfield G. Drug combinations and impaired renal function-the "triple whammy". Br J Clin Pharmacol 2005;59:239-43.

25 Thomas M. Diuretics, ACE inhibitors and NSAIDs-the triple whammy. Med J Aust 2000;172:184-5.

26 Huerta C, Castellsague J, Varas-Lorenzo C, Rodriguez LAG. Nonsteroidal anti-inflammatory drugs and risk of ARF in the general population. Am J Kid Dis 2005;45:531-9.

27 Gislason GH, Rasmussen JN, Abildstrom SZ, Schramm TK, Hansen ML, Fosbol EL, et al. Increased mortality and cardiovascular morbidity associated with use of nonsteroidal anti-inflammatory drugs in chronic heart failure. Arch Intern Med 2009;169:141-9.

28 Medicines and Healthcare Products Regulatory Agency, Commission on Human Medicines. Conventional (typical) antipsychotics: increased mortality in dementia. Drug Saf Update 2008;2:5.

29 Adams J. The reliability of provider profiling: a tutorial. RAND, 2009.

30 Roland M, Elliott M, Lyratzopoulos G, Barbiere J, Parker RA, Smith P, et al. Reliability of patient responses in pay for performance schemes: analysis of national General Practitioner Patient Survey data in England. BMJ 2009;339:b3851.

31 Hofer TP, Hayward RA, Greenfield S, Wagner EH, Kaplan SH, Manning WG. The unreliability of individual physician "report cards" for assessing the costs and quality of care of a chronic disease. JAMA 1999;281:2098-105.

32 Snijders T, Bosker R. Multilevel analysis: an introduction to basic and advanced multilevel modeling. Sage, 1999.

33 Spiegelhalter D. Funnel plots for comparing institutional performance. Stat Med 2005;24:1185-202

34 Larsen K, Merlo J. Appropriate assessment of neighbourhood effects on individual health: integrating random and fixed effects in multilevel logistic regression. Am J Epidemiol 2007;161:81-8.

35 National Patient Safety Agency National Reporting and Learning Service. Never events: framework update for 2010/11. NPSA, 2010.

36 Kirk S, Parker D, Claridge T, Esmail A, Marshall M. Patient safety culture in primary care: developing a theoretical framework for practical use. Qual Saf Health Care 2007:16:313-20.

37 Craig P, Dieppe P, Macintyre S, Michie S, Nazareth I, Petticrew M. Developing and evaluating complex interventions: the new Medical Research Council guidance. BMJ 2008:337:979-83.

38 Fernando B, Savelyich BSP, Avery AJ, Sheikh A, Bainbridge M, Horsfield P, et al. Prescribing safety features of general practice computer systems: evaluation using simulated test cases. BMJ 2004;328:1171-2.

39 Lilford R, Mohammed AM, Spiegelhalter D, Thomson R. Uses and abuses of outcome data in managing performance of acute medical care: avoiding institutional stigma. Lancet 2004;363:1147-54.

Accepted: 7 April 2011

Cite this as: BMJ 2011;342:d3514 


\section{Tables}

\section{Table 1| Indicator definitions}

\section{Measure name}

Numerator definition

NSAID prescribed in patient with peptic ulcer without gastroprotection ${ }^{1519}$

\section{NSAID prescribed in over $75 \mathrm{~s}$ without} gastroprotection ${ }^{15} 19$

NSAID prescribed in over 65 s prescribed angiotensin converting enzyme inhibitor or angiotensin receptor blocker and diuretic ${ }^{2425}$

\section{NSAID prescribed in over $65 \mathrm{~s}$ with estimated} glomerular filtration rate $<60^{1526}$
No of patients prescribed oral NSAID in past year without prescription of gastroprotective drug in eight weeks before prescription of NSAID

No of patients prescribed NSAID in past 12 weeks without prescription of gastroprotective drug in eight weeks before prescription of NSAID

No of patients prescribed NSAID in past 12 weeks ("triple whammy")

No of patients prescribed NSAID in past 12 weeks

\section{Denominator definition}

No of patients with $\geq 1$ year history of peptic ulce disease

No of patients aged $\geq 75$ prescribed NSAID in past 12 weeks

No of patients aged $\geq 65$ prescribed angiotensin converting enzyme inhibitor or angiotensin receptor blocker and diuretic in past 12 weeks

No of patients aged $\geq 65$ with stage 3,4 , or 5 renal impairment (estimated glomerular filtration rate $<60$ )

NSAID, antiplatelet, high risk antibiotic, or oral No of patients co-prescribed one of specified drugs in past year No of patients prescribed warfarin in past 12 azole antifungal prescribed to current warfarin user $^{1523}$ while taking warfarin. Co-prescription defined as both drugs weeks

prescribed on same day in past year, or prescription of high risk

drug between two warfarin prescriptions in past year-that is,

although measure includes only those currently taking warfarin,

co-prescription in past year has to occur while patients were

receiving warfarin. High risk antibiotics defined as macrolides,

quinolones, and metronidazole

NSAID, tricyclic, thiazolidinedione, or other "drug No of patients prescribed at least one of specified drugs in past No of patients with diagnosis of heart failure to avoid" prescribed to patient with heart failure ${ }^{16}$ year. Other "drugs to avoid" are tadalafil, disulfiram, minoxidil, recorded at time of last prescription 1727 and class I and III antiarrhythmics, except amiodarone, verapamil, diltiazem, and itraconazole

Methotrexate not prescribed with explicit instruction to take weekly ${ }^{15}$ No of patients without an explicitly weekly dose instruction on No of patients prescribed methotrexate in past 12 last prescription weeks

Methotrexate $2.5 \mathrm{mg}$ and $10 \mathrm{mg}$ co-prescription ${ }^{15}$ No of patients co-prescribed $10 \mathrm{mg}$ and $2.5 \mathrm{mg}$ methotrexate No of patients prescribed methotrexate in past 12 tablets on last prescription weeks

Risperidone/olanzapine* prescribed in over 65 s No of patients prescribed olanzapine or risperidone in past 12 No of patients aged $\geq 65$ with diagnosis of with dementia but not psychosis ${ }^{1428} \quad$ weeks dementia recorded at time of last prescription but with no diagnosis of psychosis recorded at time of last prescription

NSAID=non-steroidal anti-inflammatory drug.

${ }^{*}$ Reflects national guidance at time care was delivered. More recent guidance is that all antipsychotics are contraindicated in older people with dementia except for risperidone for short term treatment of aggression. 


\begin{tabular}{|c|c|c|c|c|c|}
\hline Prescribing safety indicator & $\begin{array}{l}\text { No of patients receiving } \\
\text { high risk prescription/No } \\
\text { of patients particularly } \\
\text { vulnerable to ADE }\end{array}$ & $\%(95 \% \mathrm{Cl})$ & $\begin{array}{l}\text { Reliability for } \\
\text { practice with } \\
\text { median } \\
\text { denominator size }\end{array}$ & $\begin{array}{l}\% \text { of practices } \\
\text { with reliability } \\
\quad>0.7\end{array}$ & $\begin{array}{l}\% \text { of practices } \\
\text { with reliability } \\
\qquad 0.8\end{array}$ \\
\hline $\begin{array}{l}\text { NSAID prescribed in patient with peptic ulcer } \\
\text { disease without gastroprotection }\end{array}$ & $4371 / 49574$ & $8.8(8.6$ to 9.1$)$ & 0.84 & 77.5 & 59.7 \\
\hline $\begin{array}{l}\text { NSAID prescribed in patients } 75 \text { and over } \\
\text { without gastroprotection }\end{array}$ & $4464 / 8840$ & 50.5 (49.5 to 51.5$)$ & 0.64 & 31.7 & 7.6 \\
\hline $\begin{array}{l}\text { NSAID prescribed in patients aged } 65 \text { and } \\
\text { over prescribed angiotensin converting } \\
\text { enzyme inhibitor or angiotensin receptor } \\
\text { blocker and diuretic }\end{array}$ & $3908 / 44492$ & $8.8(8.5$ to 9.0$)$ & 0.88 & 90.5 & 79.4 \\
\hline $\begin{array}{l}\text { NSAID prescribed in patients aged } 65 \text { and } \\
\text { over with estimated glomerular filtration rate } \\
<60\end{array}$ & $2272 / 27668$ & $8.2(7.1$ to 9.3$)$ & 0.76 & 61.6 & 40.3 \\
\hline NSAID prescribed to current warfarin user & $550 / 16182$ & 3.4 (3.1 to 3.7$)$ & 0.86 & 86.0 & 72.7 \\
\hline Antiplatelet prescribed to current warfarin user & $1554 / 16182$ & $9.6(9.2$ to 10.1$)$ & 0.76 & 66.7 & 36.8 \\
\hline $\begin{array}{l}\text { High risk antibiotic prescribed to current } \\
\text { warfarin user }\end{array}$ & $1271 / 16182$ & $7.9(6.4$ to 9.3$)$ & 0.67 & 42.2 & 13.3 \\
\hline $\begin{array}{l}\text { Oral azole antifungal prescribed to current } \\
\text { warfarin user }\end{array}$ & $116 / 16182$ & 0.7 (0.6 to 0.8$)$ & 0.74 & 60.3 & 29.2 \\
\hline NSAID prescribed to patient with heart failure & $2181 / 19052$ & $11.4(11.0$ to 11.9$)$ & 0.73 & 59.4 & 33.6 \\
\hline Tricyclic prescribed to patient with heart failure & $1246 / 19052$ & $6.5(6.2$ to 6.9$)$ & 0.74 & 60.3 & 35.9 \\
\hline $\begin{array}{l}\text { Thiazolidinedione prescribed to patient with } \\
\text { heart failure }\end{array}$ & $278 / 19052$ & $1.5(1.3$ to 1.6$)$ & 0.80 & 71.1 & 47.3 \\
\hline $\begin{array}{l}\text { Other "drugs to avoid" prescribed to patient } \\
\text { with heart failure } †\end{array}$ & $87 / 19052$ & $0.5(0.4$ to 0.6$)$ & 0.90 & 91.7 & 80.3 \\
\hline $\begin{array}{l}\text { Methotrexate not prescribed with explicit } \\
\text { instruction to take weekly }\end{array}$ & $92 / 3487$ & 2.6 (2.1 to 3.2$)$ & 0.76 & 58.1 & 36.8 \\
\hline $\begin{array}{l}\text { Methotrexate } 2.5 \mathrm{mg} \text { and } 10 \mathrm{mg} \\
\text { co-prescription }\end{array}$ & $410 / 3487$ & $11.8(10.7$ to 12.8$)$ & 0.69 & 45.4 & 19.0 \\
\hline $\begin{array}{l}\text { Risperidone/olanzapine prescribed in over } \\
65 \text { s with dementia but not psychosis }\end{array}$ & $288 / 10171$ & 2.8 (2.5 to 3.2$)$ & 0.84 & 76.5 & 62.2 \\
\hline $\begin{array}{l}\text { Patients with at least one high risk prescription } \\
\text { (all indicators) }\end{array}$ & $19308 / 139404$ & $13.9(13.7$ to 14.0$)$ & 0.92 & 95.6 & 88.2 \\
\hline
\end{tabular}

$A D E=$ adverse drug event; NSAID=non-steroidal anti-inflammatory drug.

${ }^{*}$ Reliability coefficient can vary between 0 (completely unreliable) and 1 (completely reliable). Values greater than 0.7 are generally considered as indicating acceptable reliability, although for high stakes evaluation, reliabilities of 0.8-0.9 are preferable.

†Other "drugs to avoid" are tadalafil, disulfiram, minoxidil, and class I and III antiarrhythmics, except amiodarone, verapamil, diltiazem, and itraconazole. 


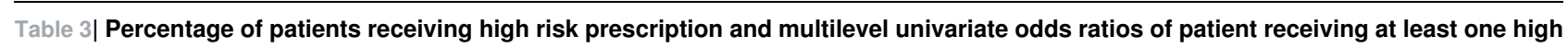
risk prescription

\begin{tabular}{|c|c|c|}
\hline$\%$ receiving any high $r$ & prescription $(95 \% \mathrm{Cl})$ & Multilevel univariate odds ratio $(95 \% \mathrm{Cl})$ \\
\hline \multicolumn{3}{|l|}{ Patient level fixed effects (No of patients) } \\
\hline \multicolumn{3}{|l|}{ Age: } \\
\hline$<40(3870)$ & 6.7 (5.9 to 7.5$)$ & 1 \\
\hline $40-49(8108)$ & $8.4(7.8$ to 9.0$)$ & $1.30(1.12$ to 1.51$)$ \\
\hline $50-59$ (13 242) & $12.6(12.0$ to 13.1$)$ & 2.04 (1.78 to 2.34$)$ \\
\hline $60-69$ (27 238) & $14.4(14.0$ to 14.8$)$ & 2.38 (2.08 to 2.71$)$ \\
\hline $70-79(47663)$ & $15.9(15.6$ to 16.2$)$ & 2.69 (2.36 to 3.06$)$ \\
\hline$\geq 80$ (39 283) & $13.2(12.9$ to 13.6$)$ & 2.20 (1.93 to 2.51$)$ \\
\hline \multicolumn{3}{|l|}{ Sex: } \\
\hline Male (67 204) & $13.1(12.9$ to 13.3$)$ & 1 \\
\hline Female (72 200) & $14.6(14.3$ to 14.8$)$ & $1.14(1.10$ to 1.17$)$ \\
\hline \multicolumn{3}{|l|}{ Carstairs deprivation fifth: } \\
\hline 1 (affluent) (24 392) & $12.8(12.4$ to 13.2$)$ & 1 \\
\hline $2(30204)$ & $13.0(12.7$ to 13.4$)$ & 1.05 (0.99 to 1.12$)$ \\
\hline $3(32$ 033) & $14.0(13.6$ to 14.4$)$ & 1.05 (0.98 to 1.12$)$ \\
\hline $4(26946)$ & $14.1(13.7$ to 14.5$)$ & $1.08(1.02$ to 1.16$)$ \\
\hline 5 (deprived) (25 829) & $15.3(14.8$ to 15.7$)$ & $1.10(1.03$ to 1.18$)$ \\
\hline \multicolumn{3}{|l|}{ No of active repeat drugs: } \\
\hline $0(19082)$ & $4.3(4.1$ to 4.7$)$ & 1 \\
\hline 1 or $2(21709)$ & $11.0(10.5$ to 11.4$)$ & 2.68 (2.47 to 2.91$)$ \\
\hline 3 or $4(30460)$ & $12.7(12.3$ to 13.1$)$ & 3.18 (2.94 to 3.43$)$ \\
\hline 5 or 6 (30 345) & $14.5(14.1$ to 14.9$)$ & 3.69 (3.42 to 3.99$)$ \\
\hline 7 or $8(20445)$ & $18.3(17.8$ to 18.8$)$ & 4.87 (4.50 to 5.27$)$ \\
\hline 9 or 10 (10 372) & 21.5 (20.7 to 22.3$)$ & $5.92(5.44$ to 6.45$)$ \\
\hline$\geq 11(6991)$ & $26.6(25.5$ to 27.6$)$ & 7.81 (7.15 to 8.54$)$ \\
\hline \multicolumn{3}{|l|}{ Practice level fixed effects (No of practices*) } \\
\hline \multicolumn{3}{|l|}{ List size fourth: } \\
\hline $512-4675(79)$ & $15.4(14.7$ to 16.0$)$ & 1 \\
\hline 4676-7318 (79) & $14.8(14.4$ to 15.2$)$ & $0.95(0.85$ to 1.07$)$ \\
\hline $7319-9875$ (79) & $13.9(13.5$ to 14.2$)$ & $0.88(0.79$ to 0.99$)$ \\
\hline $9876-21440(78)$ & $13.2(12.9$ to 13.4$)$ & $0.82(0.73$ to 0.92$)$ \\
\hline \multicolumn{3}{|l|}{ Contract: } \\
\hline New General Medical Services (270) & $14.0(13.8$ to 14.2$)$ & 1 \\
\hline 2c or 17c (Personal Medical Services) (39) & $12.3(11.8$ to 12.8$)$ & $0.88(0.78$ to 1.00$)$ \\
\hline \multicolumn{3}{|l|}{ Training: } \\
\hline Yes (105) & $12.5(12.2$ to 12.8$)$ & 1 \\
\hline No (204) & 14.9 (14.6 to 15.2$)$ & 1.19 (1.10 to 1.28$)$ \\
\hline \multicolumn{3}{|l|}{ Dispensing: } \\
\hline No $(276)$ & $14.2(13.6$ to 14.0$)$ & 1 \\
\hline Yes (33) & $13.8(13.3$ to 15.1$)$ & $1.09(0.94$ to 1.26$)$ \\
\hline \multicolumn{3}{|l|}{ Single handed: } \\
\hline No (282) & $13.8(13.6$ to 14.0$)$ & 1 \\
\hline Yes (27) & $15.0(13.8$ to 16.2$)$ & $1.07(0.90$ to 1.26$)$ \\
\hline \multicolumn{3}{|l|}{ Rurality/remoteness: } \\
\hline Primary city (111) & $12.6(12.3$ to 12.9$)$ & 1 \\
\hline Urban area (88) & 14.6 (14.3 to 14.9$)$ & 1.16 (1.06 to 1.28$)$ \\
\hline Accessible area $(70)$ & $14.6(14.1$ to 15.0$)$ & 1.20 (1.07 to 1.33$)$ \\
\hline Remote area (15) & $15.0(14.2$ to 15.7$)$ & $1.19(0.99$ to 1.42$)$ \\
\hline
\end{tabular}




\section{Table 3 (continued)}

Variable $\quad \%$ receiving any high risk prescription $(95 \% \mathrm{Cl})$ Multilevel univariate odds ratio $(95 \% \mathrm{Cl})$

Very remote area (31) $13.5(12.8$ to 14.1$)$ $1.02(0.89$ to 1.18$)$

Maximum QOF points for medicines 10-12:

\begin{tabular}{lcc} 
Yes $(292)$ & $13.7(13.5$ to 13.9$)$ & 1 \\
\hline No $(17)$ & $16.4(15.5$ to 17.3$)$ & $1.13(0.95$ to 1.35$)$ \\
\hline
\end{tabular}

QOF=Quality and Outcomes Framework.

*Practice level data were unavailable for $6(1.9 \%)$ practices with $2139(1.5 \%)$ patients. 
Table 4 | Multivariate odds ratios of patient receiving one or more high risk prescriptions

\begin{tabular}{|c|c|c|}
\hline \multirow[b]{2}{*}{ Variable } & \multicolumn{2}{|c|}{ Odds ratio $(95 \% \mathrm{Cl})$} \\
\hline & $\begin{array}{l}\text { Model } 1 \text { patient level variables only (315 practices, } 139 \\
\qquad 404 \text { patients) }\end{array}$ & $\begin{array}{l}\text { Model } 2 \text { patient and practice level variables (309 practices, } 137 \\
\qquad 265 \text { patients }{ }^{\star} \text { ) }\end{array}$ \\
\hline \multicolumn{3}{|c|}{ Patient level fixed effects } \\
\hline \multicolumn{3}{|l|}{ Age: } \\
\hline$<40$ & 1 & 1 \\
\hline $40-49$ & $1.12(0.96$ to 1.30$)$ & $1.12(0.96$ to 1.30$)$ \\
\hline $50-59$ & 1.35 (1.18 to 1.56$)$ & $1.35(1.18$ to 1.56$)$ \\
\hline $60-69$ & $1.16(1.01$ to 1.33$)$ & $1.16(1.01$ to 1.33$)$ \\
\hline 70-79 & $1.18(1.03$ to 1.35$)$ & $1.18(1.03$ to 1.35$)$ \\
\hline$\geq 80$ & 0.98 (0.86 to 1.13$)$ & $0.98(0.85$ to 1.12$)$ \\
\hline \multicolumn{3}{|l|}{ Sex: } \\
\hline Male & 1 & 1 \\
\hline Female & 1.05 (1.02 to 1.08$)$ & $1.05(1.02$ to 1.09$)$ \\
\hline \multicolumn{3}{|c|}{ No of active repeat drugs: } \\
\hline 0 & 1 & 1 \\
\hline $1-2$ & 2.69 (2.47 to 2.92 ) & 2.69 (2.48 to 2.93 ) \\
\hline $3-4$ & 3.24 (2.99 to 3.52 ) & 3.25 (2.99 to 3.53 ) \\
\hline 5-6 & 3.79 (3.49 to 4.11 ) & 3.81 (3.51 to 4.13 ) \\
\hline 7-8 & 5.01 (4.61 to 5.45 ) & 5.01 (4.61 to 5.45 ) \\
\hline $9-10$ & 6.06 (5.54 to 6.63 ) & 6.08 (5.56 to 6.65 ) \\
\hline$\geq 11$ & 7.91 (7.20 to 8.69) & 7.90 (7.19 to 8.68$)$ \\
\hline \multicolumn{3}{|c|}{ Practice level fixed effects } \\
\hline \multicolumn{3}{|c|}{ Rurality/remoteness: } \\
\hline Primary city & - & 1 \\
\hline Urban area & - & $1.19(1.08$ to 1.31$)$ \\
\hline Accessible area & - & $1.14(1.02$ to 1.27$)$ \\
\hline Remote area & - & $1.15(0.97$ to 1.36$)$ \\
\hline Very remote area & - & $0.97(0.85$ to 1.11$)$ \\
\hline \multicolumn{3}{|l|}{ List size fourth: } \\
\hline $512-4675$ & - & 1 \\
\hline $4676-7318$ & - & $0.99(0.88$ to 1.11$)$ \\
\hline 7319-9875 & - & $0.93(0.82$ to 1.05$)$ \\
\hline $9876-21440$ & - & $0.85(0.75$ to 0.96$)$ \\
\hline \multicolumn{3}{|l|}{ Training: } \\
\hline Yes & - & 1 \\
\hline No & - & $1.10(1.02$ to 1.20$)$ \\
\hline
\end{tabular}

*Practice level data was unavailable for 6 (1.9\%) practices with $2139(1.5 \%)$ patients. 


\section{Figure}

- Practice observed:expected Average

- - 2 SD warning limits

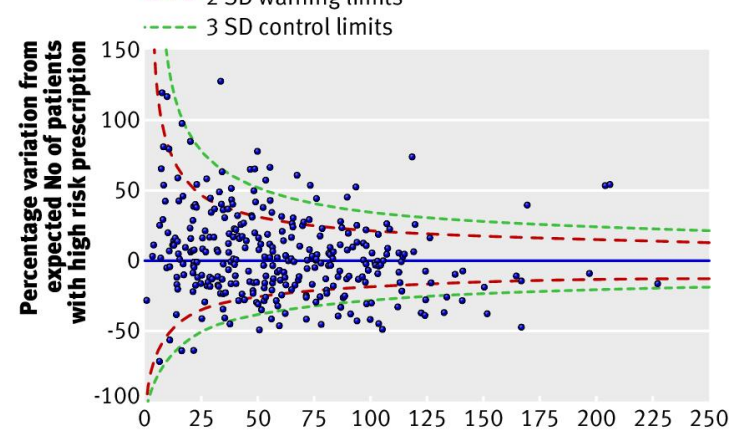

Expected No of patients with high risk prescription

Cross sectional control chart for observed versus expected number of patients with a high risk prescription. Practices lying outside 3 SD control limit are statistically significantly different from average 